Jurnal Kepelatihan

Olahraga
Jurnal Kepelatihan Olahraga, Universitas Pendidikan Indonesia

Journal homepage: http://ejournal.upi.edu/index.php/JKO

Volume 11, No. 2, September 2019

p-ISSN 2086-339X / e-ISSN 2657-1765

\title{
Perbandingan Pengaruh Latihan Squat Jump dan Plyometric Jump to Box terhadap Peningkatan Power Otot Tungkai
}

\author{
Muhamad Iqbal Pratama ${ }^{1 *}$, Bambang Erawan ${ }^{1}$ \\ ${ }^{1}$ Pendidikan Kepelatihan Olahraga, Fakultas Pendidikan Olahraga dan Kesehatan, Universitas \\ Pendidikan Indonesia, Bandung, Indonesia \\ *iqbal28muhamad@gmail.com
}

\begin{abstract}
A B S T R A C T S
Football is a sport that requires good leg muscle power, therefore training needs to be given to increase leg muscle power. This study aims to knowing the effect of squat jump and plyometric jump to box exercises on increase in leg muscle power.The research method used in this study is an experimental method, with sampling techniques using purposive sampling. The subject was student of Sekolah Sepak Bola (SSB) KU-16 years was 16 people. The research instrument used is the vertical jump test. Based on the vertical jump result, squat jump excercise group and plyometric jump to box excercise had an significant effect on increasing leg muscle power. But the comparison of the two excercise was not significant. The conclusion that the squat jump and plyometric jump to box excercise can increasing leg muscle power.
\end{abstract}

(C) 2019 Tim Pengembang Jurnal Kepelatihan Olahraga

\begin{tabular}{l}
\hline A B S T R A K \\
\hline Sepak bola merupakan olahraga yang membutuhkan power otot tungkai \\
yang baik, oleh karena itu perlu diberikan latihan untuk meningkatkan \\
power otot tungkai. Penelitian ini bertujuan untuk mengetahui \\
perbandingan pengaruh dari latihan squat jump plyometric jump to box \\
terhadap peningkatan power otot tungkai Metode penelitian yang \\
digunakan dalam penelitian ini adalah metode eksperimental, dengan \\
teknik pengambilan sampel mengunakan teknik purposive sampling. \\
Subjek yang diambil adalah siswa Sekolah Sepak Bola (SSB) KU-16 tahun \\
berjumlah 16 orang. Instrumen penelitian yang digunakan adalah tes \\
vertical jump. Berdasarkan hasil tes vertical jump, kelompok latihan squat \\
jump dan plyometric jump to box memiliki pengaruh yang signifikan \\
terhadap peningkatan power otot tungkai. Namun perbandingan dari kedua \\
latihan tersebut tidak signifikan. Kesimpulannya bahwa latihan squat jump \\
dan plyometric jump to box dapat meningkatkan power otot tungkai.
\end{tabular}

\author{
ARTICLE INFO \\ Article History: \\ Received 15 Mei 2019 \\ Revised 10 June 2019 \\ Accepted 18 June 2019 \\ Available online 30 Sept 2019 \\ Keyword: \\ Leg muscle power, \\ Plyometric jump to box, \\ and Squat jump.
}

INFO ARTIKE L

Riwayat Artikel:

Diterima 15 Mei 2019

Direvisi 10 Juni 2019

Diterima 18 Juni 2019

Tersedia online 30 Sept 2019

Kata Kunci:

Power otot tungkai,

Plyometric jump to box, dan Squat jump. 


\section{PENDAHULUAN}

Sepak bola merupakan cabang olahraga permainan yang banyak di gemari oleh seluruh kalangan masyarakat. Sepak bola dimainkan oleh 11 orang di setiap tim yang dibagi menjadi beberapa posisi yang sesuai dengan tugasnya masing-masing, Sama seperti cabang olahraga lainnya, sepak bola memiliki teknik-teknik dasar seperti menendang, menghentikan, menggiring, menyundul, merampas, lemparan ke dalam, dan menjaga gawang.

Sepak bola merupakan jenis olahraga yang menuntut para atletnya menguasai teknik dan memiliki kondisi fisik yang baik, tanpa mengabaikan aspek taktik dan mental. Komponen fisik tersebut adalah daya tahan kardiovaskuer, daya tahan kekuatan, kekuatan otot (strength), kelentukan (flexibility), kecepatan (speed), stamina, kelincahan (agility), daya ledak otot (power), dan daya tahan kekuatan (strength endurance) (Harsono, 2015, hlm 40).

Dilihat dari karakteristik permainan sepak bola, banyak sekali teknik dasar sepak bola yang memerlukan power yang baik. Dalam hal ini power yang dominan adalah pada bagian otot tungkai. Power otot tungkai ini berperan penting dalam berbagai macam teknik dasar sepak bola itu sendiri, seperti shooting, passing, heading, jumping, dan lain sebagainya (Soemardiawan, 2017).

Banyak sekali bentuk latihan untuk melatih kekuatan power otot tungkai, Salah satunya adalah latihan plyometrics, penelitian Irawan D.S. (2017) menyatakan bahwa latihan plyometric selama 6 minggu dapat meningkatkan power tubuh bagian bawah secara signifikan. Latihan plyometric ini banyak sekali jenisnya yang tentunya disesuaikan dengan bagian yang ingin kita latih. Salah satu bentuk latihan plyometric untuk melatih power otot tungkai adalah squat jump dan plyometric jump to box. Hal ini selaras dengan penelitian Santosa, D.W. (2015) menyatakan bahwa latihan squat jump dengan interval pendek mampu meningkatkan power otot tungkai. Selain itu penelitian selanjutnya yang dilakuakan oleh Eknal, dkk. (2016) menyatakan bahwa latihan plyometric jump to box, front box jump, dan depth jump berpengaruh terhadap peningkatan power tungkai dan kecepatan.

Sampai saat ini belum ada penelitian yang mencoba untuk membandingkan metode latihan squat jump dan plyometric jump to box terhadap peningkatan power otot tungkai, sehingga peneliti tertarik untuk mencoba membandingkan pengaruh dari kedua metode tersebut terhadap peningkatan power otot tungkai siswa Sekolah Sepak Bola (SSB).

\section{METODE}

Metode yang digunakan dalam penelitian ini adalah metode eksperimen, dengan desain penelitian one group pre test-post test. Dalam penelitian ini peneliti menggunakan tes vertical jump dengan koefisien reliabilitas 0,93 dan validitas 0,78 .

Analisis data dilakukan dengan bantuan software statistik yaitu Statistical Product and Service Solution (SPSS) seri 24. Teknik analisis yang di gunakan adalah, uji statistik deskriptif , uji normalitas, uji homogenitas, uji paired-sample $t$ test, dan uji independent-sample t test. 


\subsection{Subjek Penelitian}

Populasi dalam penelitian ini adalah siswa yang terdaftar di SSB, dengan teknik pengambilan sampel yang dipakai adalah purposive sampling yaitu siswa SSB KU-16 yang berjumlah 16 orang.

\subsection{Prosedur Penelitian}

Penelitian dilaksanakan selama 5 minggu, dengan frekuensi pertemuan tiga kali dalam seminggu. Setiap minggunya beban latihan yang diberikan kepada subjek di tambah baik itu dari sisi volume maupun intensitas yang telah di tentukan di program latihan.

Pertama, subjek melakukan Pre test dengan menggunakan test vertical jump yang bertujuan untuk mengukur seberapa kuat daya ledak (power) otot tungkai subjek. Alat yang disiapkan papan vertical jump, serbuk kapur, dan alat tulis. Pelaksanaan test diawali dengan subjek terlebih dahulu mengoleskan ujung jari ke serbuk kapur/ magnesium karbonat, kemudian berdiri tegak dekat dingding, kaki rapat, papan skala berada pada sisi kanan atau kiri badan subjek, angkat tangan di tempelkan pada papan skala hingga meninggalkan bekas jari, Subjek mengambil awalan dengn sikap menekukkan lutut dan kedua lengan diayunkan ke belakang, kemudian subjek meloncat setinggi mungkin sambil menepuk papan dengan tangan yang terdekat dan telah di olesi serbuk, sehingga menimbukan bekas. Subjek di beri 3 kali kesempatan.

Kedua, setelah data tes awal terkumpul, kemudian subjek di urutkan dari nilai tertinggi sampai terendah. Setelah rangking di dapat, subjek dikelompokan dengan teknik ABBA untuk menentukan treatment yang akan diberikan kepada setiap kelompok. Kelompok treatment dibagi menjadi dua kelompok, kelompok A diberikan treatment squat jump sedangkan kelompok B diberikan treatment plyometric jump to box.

Ketiga, subjek yang telah dibagi menjadi 2 kelompok kemudian di berikan treatment selama 16 kali pertemuan. Treatment yang diberikan adalah latihan squat jump dan plyometric jump to box yang telah ditentukan volume dan intensitasnya.

Keempat, subjek melakukan Post test Pelaksanaan test sama dengan test awal. Setelah data terkumpul dari hasil pre test dan post test, kemudian dilakukan analisis data untuk mengetahui perbandingan dari latihan squat jump dan plyometric jump to box terhadap peningkatan power otot tungkai .

\section{HASIL PENELITIAN}

Tabel 3.1 Perbandingan hasil vertical jump (cm) pada kelompok squat jump dan plyometric jump to box.

Data mean \pm Standard Deviation

\begin{tabular}{cccc}
\hline Kelompok & Pre Tes & Post Tes & Selisih \\
\hline \multirow{2}{*}{ Squat Jump } & $49.87 \pm$ & $58.5 \pm$ & $8.63 \pm 1.6$ \\
& 9.85 & 8.62 & \\
\hline \multirow{2}{*}{ Jump to Box } & $49.5 \pm$ & $59.25 \pm$ & $9.75 \pm$ \\
& 9.58 & 8.55 & 2.23 \\
\hline
\end{tabular}

Berdasarkan tabel 3.1 dapat diketahui bahwa nilai rata-rata tes awal dari kelompok squat jump adalah 49,87 dengan std. Deviasi 9,85. Untuk nilai rata-rata tes awal plyometric jump to box adalah 49,5 dengan std. Deviasi 9,58. Sedangakan rata-rata hasil tes akhir dari kelompok squat jump adalah 58,5 dengan std. Deviasi 8,62. Rata-rata tes akhir plyometric jump to box sebesar 59,25 dengan std. Deviasi 8,55. 


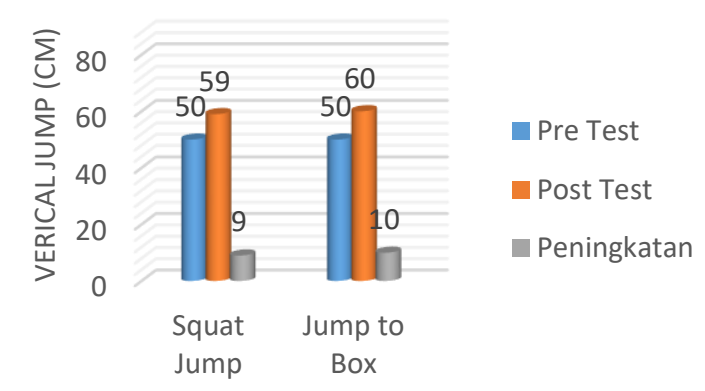

Gambar 3.1. Perbandingan hasil vertical jump pada kelompok squat jump dan plyometric plyometric jump to box.

Berdasarkan gambar 3.1 Peningkatan dari kelompok squat jump dilihat dari hasil rata-rata tes awal da akhir adalah 9, sedangkan untuk plyometric jump to box sebesar 10.

Setelah diketahui deskripsi data dari kelompok squat jump dan plyometric jump to box, dilakukan pengujian hipotesis untuk mengetahui perbandingan dari kedua kelompok tersebut, uji hipotesis yang di pakai adalah uji independentsample t test.

Tabel 3.2 independent-sample t test

\begin{tabular}{cccc}
\hline & $\mathrm{t}$ & $\mathrm{Df}$ & Sig (2-tailed) \\
\hline Perabandingan & -1.152 & 14 & .268 \\
\hline
\end{tabular}

Berdasarkan tabel 3.2, diketahui $\mathrm{T}_{\text {hitung }}$ sebesar -1,152 dengan df 14 pada taraf $\alpha 0,05$ maka $\mathrm{T}_{\text {hitung }}-1,152<-2,145$ dengan nilag sig (2Tailed) > 0,05 yang berarti tidak terdapat pengaruh yang signifikan.

\section{PEMBAHASAN}

Setelah melakukan pengolahan data dan analisa data, terdapat pengaruh yang signifikan dari latihan squat jump dan jump to box terhadap peningkatan power otot tungkai. Hasi penelitian ini selaras dengan pernyataan Chu \& Myer (2013, hlm 14) menyebutkan bahwa latihan plyometric merupakan latihan yang mampu meningkatkan kekuatan otot secara maksimal dalam waktu yang sesingkat mungkin. Selain itu latihan plyometric merupakan latihan yang sempurna untuk meningkatkan kekuatan otot yang membutuhkan sprint, dengan latihan yang dilakukan selama 12 minggu (Ari \& Çolakoğlu, 2017).

Latihan squat jump yang di berikan kepada subjek berpengaruh terhadap peningkatan power otot tungkai. Gerakan dari latihan tersebut mampu meningkatkan daya ledak otot tungkai, mengingat squat jump di dominasi oleh gerakan melompat yang berulang, dimana beban tubuh bertumpu pada kaki, Setiap kali mendarat setelah melompat, otot kaki senantiasa terlatih untuk terus melakukan kontraksi-kontraksi, khususnya kontraksi concentric dan eccentric (Mahfuz, 2016). Berdasarkan penelitian Kamble dan Kazi (2017) menyatakan bahwa latihan squat jump selama 6 minggu efektif dalam meningkatkan tinggi lompatan.

Latihan plyometric jump to box yang diberikan kepada subjek berpengaruh terhadap power otot tungkai. Secara fisologi gerakan plyometric jump to box menyebabkan terjadinya reflek regang (stretch reflex). Reflek regang ini merupakan respon terhadap tingkat peregangan otot yang diberikan dan merupakan salah satu reflek tercepat pada tubuh manusia (Hanafi S., 2010) Latihan ini memungkinkan otot tertahan diatas box / rintangan yang memungkin kinerja otot lebih maksimal. Berdasarkan penelitian Eknal, dkk. (2016) menyatakan bahwa latihan plyometric jump to box, front box jump, dan depth jump berpengaruh terhadap peningkatan power otot tungkai dan kecepatan. 
Berdasarkan hasil penelitian diatas, tidak ada perbedaan yang signifikan dari latihan squat jump dan plyometric jump to box terhadap peningkatan power otot tungkai. Dalam hal ini latihan plyometric jump to box lebih menguras tenaga, karena gerakannya yang eksflosif lompat ke box, sehingga subjek lebih cepat lelah jika di bandingkan dengan latihan squat jump.

Penelitian sebelumnya yang dilakukan oleh Gusfirnando, Dynel. dkk. (2015) mengemukakan bahwa latihan box jump lebih baik untuk meningkatkan power otot tungkai dibandingkan dengan latihan split squat jump.

\section{KESIMPULAN DAN SARAN}

Berdasarkan hasil pengolahan dan analisis data, maka kesimpulan dari penelitian Perbandingan Pengaruh Latihan Squat jump dan Plyometric plyometric jump to box terhadap peningkatan Power otot tungkai adalah terdapat pengaruh latihan squat jump dan plyometric plyometric jump to box terhadap peningkatan power otot tungkai, sedangkan perbandingan peningkatan hasil latihan squat jump dan plyometric jump to box terhadap peningkatan power otot tungkai tidak signifikan.

Berdasarkan hasil penelitian ini, maka saran-saran yang dapat diberikan adalah sebagai berikut, untuk para pelatih hendaknya latihan plyometric ini diberikan kepada atlet, guna meningkatkan kemampuan fisik khususnya pada komponen power otot tungkai, karena yang kita ketahui otot tungkai merupakan bagian penting dalam permainan sepak bola. Bagi peneliti selanjutnya yang akan melakukan penelitian yang sejenis untuk dapat membandingkan metode latihan yang bebeda untuk meningkatkan power otot tungkai agar di peroleh informasi yang semakin tepat terkait bentuk latihan yang paling efektif untuk meningkatkan power otot tungkai. Perlu diadakan penelitian lebih lanjut mengenai volume dan intensitas dalam latihan plyometric ini agar penelelitian selanjutnya lebih baik lagi.

\section{DAFTAR PUSTAKA}

Ari, Y. \& Çolakoğlu, F. F. (2017). The Effect of 12-Week Plyometric Training Program on Anaerobic Power, Speed, Flexibility and Agility for Adolescent Footbal Player. Eroupean Journal of Physical Education and Sport Science, 3 (5), hlm 44-64.

Chu. D.A. \& Myer G.D. (2013). Plyometric. United States of America: Sheridan Books.

Eknal, dkk. (2016). Pengaruh Latihan Jump To Box, Front Box Jump, dan Depth Jump Terhadap Peningkatan Explosive Power Otot Tungkai dan Kecepatan. Jurnal Media Ilmu Keolahragaan Indonesia, 6 (1), hlm 9-14.

Gusfirnando, dkk. (2015). Pengaruh Latihan Split Squat Jump dan Box Jump Terhadap Peningkatan Daya Ledak Otot Tungkai Pada Ekstrakurikuler Bola Voli di SMKN 3 Malang. Journal Sport Science, 5 (1), tanpa halaman.

Hanafi S. (2010). Efektifitas Latihan Beban dan Latihan Pliometrik Dalam Meningkatkan Kekuatan

Otot Tungkai dan Kecepatan Reaksi. Jurnal Ilmu Keolahrgaan (ILARA), 1 (2). Hlm 1-9. Harsono. (2015). Kepelatihan Olahraga Teori dan Metodologi. Bandung : PT. Remaja Rosdakarya. 
Irawan, D.S. (2017). Six Weeks Progressive Plyometrics Training on Badminton Player's Agility. Advances in Health Sciencs Research, 2, hlm 18-21.

Kamble, K.G. \& Kazi, A.H. (2017). Effect Of Squat Jump Training On Performance Of High Jumping In Young Female Students. International Journal of Multidisciplinary Research and Development, 4 (2), hlm 162-164.

Mahfuz. (2016). Pengaruh Latihan Split Squat Jump dan Standing Jump and Reach Terhadap Kekuatan dan Power Otot Tungkai. Journal of Phisical Education, Health, and Sport, 3 (2), hlm 83-95. Santosa, D.W. (2015). Pengaruh Pelatihan Squat Jump Dengan Metode Interval Pendek Terhadap Daya Ledak (Power) Otot Tungkai. Jurnal Kesehatan Olahraga, 3 (1), hlm 158-164.

Soemardiawan. (2017). Efektifitas Metode Latihan Multiple Box To Box Jump With Single Leg Landing Terhadap Power Otot Tungkai Pada Pemain Futsal SMAN 1 Gunungsari Tahun 2017. Jurnal Ilmiah Mandala Education, 3 (2), hlm 1-6.

Zakaria, G. \& Mudian, D.(2018). Pengaruh Latihan Plyometrics Jump To Box Terhadap Peningkatan Power Tungkai Siswa Kelas X Pada Permainan Bola Voli. BIORMATIKA Jurnal Ilmiah FKIP Universitas Subang, 4 (1), tanpa halaman. 